\title{
Social-Environmental Factors and Suicide Mortality: A Narrative Review of over 200 Articles
}

\author{
Allison Milner ${ }^{1}$, Heidi Hjelmeland ${ }^{2,3}$, Ella Arensman ${ }^{4}$, Diego De Leo ${ }^{1}$ \\ ${ }^{1}$ Australian Institute for Suicide Research and Prevention, Griffith University, Brisbane, Australia \\ ${ }^{2}$ Department of Social Work and Health Science, Norwegian University of Science and Technology, \\ Trondheim, Norway \\ ${ }^{3}$ Department of Health Surveillance and Suicide Prevention, Norwegian Institute of Public Health, Oslo, Norway \\ ${ }^{4}$ National Suicide Research Foundation and Department of Epidemiology and Public Health, \\ University College Cork, Cork, Ireland \\ Email: allison.milner@unimelb.edu.au
}

Received December $12^{\text {th }}, 2012$; revised January $26^{\text {th }}, 2013$; accepted February $9^{\text {th }}, 2013$

Copyright (C) 2013 Allison Milner et al. This is an open access article distributed under the Creative Commons Attribution License, which permits unrestricted use, distribution, and reproduction in any medium, provided the original work is properly cited.

\begin{abstract}
Suicide mortality in a population has long been thought to be sensitive to social, economic and cultural contexts. This review examined research on the relationship between social-environmental variables and suicide mortality published over a ten-year period. The main areas covered in the review included: the economy and income, unemployment, relationship status, fertility and birth rates, female participation in the workforce, religion, migration, location of residence, modernisation, media reporting, alcohol, and access to suicide methods. Results of the review indicated that rates of suicide mortality (deaths per 100,000 in a population) were sensitive to a wide range of social factors. There were relatively stable associations noted between divorce and unemployment with suicide mortality, while many of the reported associations between suicide mortality and other social variables (such as religion, fertility and female participation in the workforce) were influenced by contextual factors and time. These findings indicate the importance of considering the relationship between social factors and suicide as dynamic phenomena.
\end{abstract}

Keywords: Suicide; Social Factors; Economic Factors; Review; Durkheim; Suicide Prevention

\section{Introduction}

The relationship between suicide mortality within social, economic and cultural contexts has been a long-standing area of interest to suicide researchers. As far back as the late 1800s, it was argued that the burden of suicide in a society reflected the political, religious, economic and social environment in which the behaviour was embedded (Durkheim, 1897). According to Durkheim's (1897) social-environmental approach, a marked change to any of these environmental factors may disrupt protective and normative social roles, values and relationships, and is associated with greater risk of suicide. This seminal work has influenced hundreds of other studies, as summarised in past review papers (Moksony, 1990; Stack, 1982; Stack, 2000a, 2000b).

With the last review paper on the topic published over ten years ago, the present article aimed to provide updated evidence about the relationship between social-environmental variables and suicide in a narrative way. The central focus of the review was on those factors responsive to changes in social environments, rather than those related to climatic elements, internal psychological states or biology (e.g., mental illness and genetic differences between populations). The article particularly focused on studies assessing economic strain (changes in national income, income inequality, unemployment and modernisation) and social bonds in society (such as relationship status, fertil- ity/birth rates, gender role shifts, religion and migration). This narrative review also covered research into several other social-environmental factors shown to have an influence on suicide, including alcohol use in society (Ramstedt, 2001) and media reports of suicide (Pirkis \& Blood, 2001a, 2001b). Differences in access to lethal means used in suicide were also considered, as these have been shown to vary across social contexts (Ajdacic-Gross et al., 2008).

\section{Search Strategy}

The search strategy was conducted through five main databases: Scopus, PubMed, Proquest, Sociological Abstracts and Web of Knowledge. These databases were chosen based on the content of research covered and the scope and number of journals indexed. The search terms used in the review targeted studies focusing on the relationship between suicide and indicators of economic strain (changes in national income, unemployment etc.) and social bonds (relationship and family status etc.,). Decisions about the indicators to include in the review were based on discussion with several expert suicide researchers and the study authors. The selection of search terms and was guided by past reviews and research (Stack, 2000a, 2000b) and included "suicide mortality" and "suicide rates" in relation to the following: "economy”, "income”, "unemployment”, "relationship status”, "fertility rate”, "birth rate”, "female labour 
force participation”, “gender role”, “religion”, “migration”, "rural”, and "modernisation". The review also considered evidence about the prevalence of alcohol, access to common suicide methods, and the influence of media reporting on suicide (terms included: "alcohol”, "access to means" and "media”) as all of these areas were deemed to be sensitive to social and cultural contexts.

The search parameters of this review were set for research published from the year 2000 onwards; however, we considered older literature if no recent research was available or if an older article made an important empirical or theoretical contribution to knowledge.

The initial search results presented more than 4000 articles. Out of these, articles published in English peer-reviewed journals were considered as eligible. As empirically-based studies were the focus of the review, papers making purely conceptual or theoretical contributions were excluded. We only examined studies explicitly considering social and environmental influences on suicide mortality (usually in the form of suicide "rates" or deaths in a population).

Articles were then grouped according to subject area. Visual inspection of all abstracts was conducted in order to determine relevance to the review. At the end, there were 222 articles that were read in full for this narrative review.

\section{The Ecological Correlates of Suicide: Empirical Evidence}

\section{The Economy and Income (n = 39)}

Findings from both cross-sectional and longitudinal ecological studies indicate that suicide rates are associated with improvements and downturns in economic functioning (Baller, Levchak, \& Schultz, 2010; Berk, Dodd, \& Henry, 2006; Chuang \& Huang, 2007; Hintikka, Saarinen, \& Viinamaki, 1999; Lester \& Yang, 1997; Moniruzzaman \& Andersson, 2008; Tapia Granados \& Diez Roux, 2009; Yang \& Lester, 2001; Zhang et al., 2010). An increase in suicide rates appears to be particularly observable in locations that have experienced rapid social, political and cultural change (Maag, 2008; Milner, McClure, \& De Leo, 2012; Milner, McClure, Sun, \& De Leo, 2011), such as countries of the former USSR (Babones, 2008; Brainerd, 2001; King, Hamm, \& Stuckler, 2009) and in Asia (Chang, Gunnell, Sterne, Lu, \& Cheng, 2009; Khang, Lynch, \& Kaplan, 2005). Research also suggests the association between the economy and suicide may change over time. For example, suicide rates may initially decrease during times of economic improvement but stabilise or increase after a specific level of economic development has been reached (Yang \& Lester, 2001).

Aside from fluctuations in the economy, suicide may also be influenced by the level of income obtained in a population (Chang et al., 2011; Sareen, Afifi, McMillan, \& Asmundson, 2011; Sher, 2006). A longitudinal (1980-1998) investigation in over 60 countries found that suicide initially decreased as income per capita rose, but increased after a certain level of income was obtained (Neumayer, 2003). These results support the 'Easterlin hypothesis', which argues that human wellbeing is contingent on material conditions only until a specific level of wealth has been achieved, after which wellbeing may depend on psychological or lifestyle factors (Easterlin, 1974; Graham \& Pettinato, 2002; Pugno, 2009).

Another area of research concerns the relationship between income inequality and suicide. Researchers have argued that income inequality creates greater risk for adverse health outcomes by generating class and social differences in access to income, education, and health services (Pompili et al., 2011). The detrimental effect of income inequality may also be connected to a loss of social capital, as well as deprivation and stress (Kawachi, Kennedy, Lochner, \& Prothrow-Smith, 1997; Wilkinson, 1997). Certainly, research evidence seems to indicate that suicide is highest in those groups most disadvantaged in society (e.g. lower educational and socio-economic groups) (Daly \& Wilson, 2009; Lorant et al., 2005; Mäki \& Martikainen, 2009; Miller et al., 2005; Page, Morrell, Taylor, Carter, \& Dudley, 2006). However, there is mixed evidence about effect of income inequality at country-level, with a number of studies reporting no significant relationship with suicide mortality (Leigh \& Jencks, 2007; Lynch et al., 2001; Rodríguez Andrés, 2005), while others indicated an increase in suicide mortality (De Vogli \& Gimeno, 2009; Fernquist, 2003; Gunnell, Middleton, Whitley, Dorling, \& Frankel, 2003; Inagaki, 2010). These conflicting results may be related to methodological factors, such as problems in the use of proxy variables used to measure inequality (Babones, 2008). Variation in the relationship between inequality and suicide is also likely to reflect country-level factors, such as existing economic and political backgrounds.

\section{Unemployment $(\mathbf{n}=\mathbf{3 0})$}

While most studies have reported that higher unemployment is accompanied by an increase in suicide rates (Abe, 2004; Andres \& Halicioglu, 2010; Berk et al., 2006; Blakely, Collings, \& Atkinson, 2003; Chang, Sterne, Huang, Chuang, \& Gunnell, 2010; Chen, Yip, Lee, Fan, \& Fu, 2010; Chuang \& Huang, 2007; Corcoran \& Arensman, 2011; Fernquist, 2007; Kuroki, 2010; Lewis \& Sloggett, 1998; Lin, 2006; Milner, McClure, et al., 2012; Preti \& Miotto, 1999; Tsai \& Cho, 2011; Yamasaki, Sakai, \& Shirakawa, 2005; Ying \& Chang, 2009), a smaller number of studies have found no or mixed evidence of this association (Chang, Sterne et al., 2010; Crawford \& Prince, 1999; Lucey et al., 2005; Platt, Micciolo, \& Tansella, 1992).

These differences may be due to the fact that unemployment is influenced by individual factors associated with both the loss of a job and suicide, such as mental illness (Agerbo, 2003; Blakely et al., 2003; Jin, 1995; Noh, 2009). It is also possible that there are differences based on the length of unemployment, with several past studies finding the highest risk of suicide occurs within the first few years of unemployment and then decreases up to 16 years after the loss of a job (Lundin, Lundberg, Hallsten, Ottosson, \& Hemmingsson, 2010; Milner, Page, \& Lamontagne, 2012). The adverse effect of job-loss may be particularly accentuated during times of low unemployment in a population, as this represents a deviation from social norms (more than in times of high unemployment, when unemployment may be normative) (Lundin et al., 2010; Martikainen \& Valkonen, 1996; Milner, Page, et al., 2012). The relationship between unemployment and suicide may also be affected by other factors such as income per capita. For example, Noh (2009) found that unemployment was related to an increase in suicide rates when examined in relation to a higher income, but not when examined in relation to lower income. Political context, employment conditions and media reporting of suicide in the country have also been found to be relevant factors (Chen et al., 2010).

Past research indicates that unemployment has a stronger in- 
fluence on male suicide than female suicide (Berk et al., 2006; Blakely et al., 2003; Chan, Yip, Wong, \& Chen, 2007; Kuroki, 2010; Preti \& Miotto, 1999; Pritchard, 1992; Qin, Mortensen, Agerbo, Westergard-Nielsen, \& Eriksson, 2000). However, other research casts some doubt on these gender-specific findings (Chen et al., 2010; Kposowa, 2001). Therefore, despite some differences in results, most research suggests that unemployment increases suicide risk, but this relationship likely to be influenced by various individual and contextual factors.

\section{Relationship Status $(\mathbf{n}=27)$}

Findings from studies at both the aggregate and individual level show that divorce (Andres \& Halicioglu, 2010; Chang et al., 2011; Corcoran \& Nagar, 2010; Denney, Rogers, Krueger, \& Wadsworth, 2009; Gunnell et al., 2003; Kposowa, 2000; Leenaars \& Lester, 1999; Masocco et al., 2010; Masocco et al., 2008; Wu \& Bond, 2006), separation (Barstad, 2008; Ide, Wyder, Kolves, \& De Leo, 2011; Wyder, Ward, \& De Leo, 2009) and widowhood (Ajdacic-Gross et al., 2007; Corcoran, 2009; Denney et al., 2009; Luoma \& Pearson, 2002; Masocco et al., 2010; Masocco et al., 2008) result in a higher likelihood of suicide. In comparison, marriage is commonly found to be negatively related to suicide (Cutright \& Fernquist, 2007; Cutright, Stack, \& Ferquist, 2007; Griffiths, Ladva, Brock, \& Baker, 2008; Masocco et al., 2008; O’Reilly, Rosato, Connolly, \& Cardwell, 2008; Qin, Agerbo, \& Mortensen, 2003). Some research has suggested that male suicide is more sensitive to macro-level indicators of relationship breakdown than female suicide (Andres \& Halicioglu, 2010; Corcoran \& Nagar, 2010; Cutright \& Fernquist, 2004; Gunnell et al., 2003; Rodríguez Andrés, 2005).

However, it is likely that the protective effect of marriage is culturally specific, as research from China shows that family and relationship stress can increase the risk of suicide in married women (Zhang, 2010). Research also suggests that the association between relationship status and suicide is sensitive to social change, as well as age, gender and the time period under analysis (Messner, Bjarnason, Raffalovich, \& Robinson, 2006; Pampel, 1998; Trovato, 1987). Other individual and contextual factors also considered to be important to the association between relationship status and suicide include stigma towards help-seeking, social isolation, unemployment, and alcohol and drug use (Masocco et al., 2010). Therefore, it appears that the protective effects of relationships on suicide are related to social and cultural norms and individual factors.

\section{Birth Rates (n = 11)}

Proxy variables such as fertility and birth rates at the country level are usually found to be negatively related to suicide (Andres \& Halicioglu, 2010; Bhandarkar \& Shah, 2008; Fernquist \& Cutright, 1998; Leenaars \& Lester, 1999; Shah, 2008). These findings follow Durkheim's (1897) suggestion that parent-child relationships provide an important source of protection against suicide (Stack, 1996-1997; Umberson, 1987). However, the relationship between higher fertility/birth rates and lower suicide rates may be contingent on normative family structures in society. For example, research using the indicator of non-marital births (a proxy used to represent the weakening of the family institution) has been associated with higher suicide rates in wealthy areas of the world (Messner et al., 2006;
Stockard \& O'Brien, 2002). However, research conducted in Ireland suggests that this association was also sensitive to changes in social norms over time (Lucey et al., 2005).

\section{Female Participation in the Workforce $(n=18)$}

Studies conducted in the 1970s and 1980s found that gender role shifts, measured through indicators such as female labour force participation (FLFP), were related to higher suicide rates in wealthy areas of the world (Davis, 1981; Krupinski, 1980; Lester \& Yang, 1991; Newman, Whittemore, \& Newman, 1973). Some other studies report a mixed or changing relationship between FLFP and suicide (Burr, McCall, \& PowellGriner, 1997; Lucey et al., 2005; Stack, 1987; Trovato \& Vos, 1992), which may be because social norms and values have adjusted to female employment in high-income countries over time (i.e., as female employment does not pose a threat to normative values or roles in society) (Austin, Bologna, \& Hayama Dodge, 1992; Stack, 2000b). However, other research supports the idea that female participation in the workforce has an adverse influence on male and female suicide rates (Aliverdinia \& Pridemore, 2009; Cutright \& Fernquist, 2001a; Fernquist, 1999; Fernquist \& Cutright, 1998; Milner, McClure, et al., 2012; Neumayer, 2003; Yamasaki, Araki, Sakai, \& Voorhees, 2008). Some of the reasons for these differences may be connected to social, economic or cultural differences in the settings under study. For example, the context of female employment and suicide in Iran (Aliverdinia \& Pridemore, 2009) would be markedly different from that in high-income western countries (Cutright \& Fernquist, 2001b). These mixed findings suggest the need for more in-depth research into the relationship between suicide and gender role changes in the workforce across cultural and income groups.

\section{Religion (n = 17)}

Studies on the relationship between suicide and religion generally report a negative association, both when measured indirectly (e.g. religious book production, proportion of a specific religion in the population, ordained clergy rate) (Baller \& Richardson, 2002; Ellison, Burr, \& McCall, 1997; Fernquist, 2007; Fernquist \& Cutright, 1998) and more directly (e.g. church adherence, active membership in a religious group, strength of religious beliefs in society) (Baller \& Richardson, 2002; Cutright \& Fernquist, 2004; Ellison et al., 1997; Helliwell, 2007; Neeleman, 1997; Van Tubergen, Te Grotenhuis, \& Ultee, 2005). As with other ecological factors relevant to suicide, the relationship between religion and suicide also appears to be influenced by cultural contexts (e.g., European versus Asian areas of the world), gender and age (Clarke, Bannon, \& Denihan, 2003; Colucci \& Martin, 2008; Gearing \& Lizardi, 2009), as well as changing societal contexts and norms (Cleary \& Brannick, 2007). For example, it has been noted that religions with stronger affiliations, values and family traditions may offer greater protection against suicide (Neeleman, 1998; Neeleman \& Lewis, 1999). In agreement with Durkheim (1897), Faria and colleagues (Faria, Victora, Meneghel, De Carvalho, \& Falk, 2006) identified higher male suicide rates in predominantly Protestant regions in Rio Grande do Sul. A possible explanation is that integration and social cohesion is not as strong in Protestant societies as in Catholic societies. A study by Pritchard and Baldwin (Pritchard \& Baldwin, 2000) also 
reported important differences in respect to age, as elderly people in traditional Catholic or Orthodox locations were found to have higher suicide rates than those in less traditional states. It is also necessary to consider that religions with a strongly prohibitive attitude toward suicide may reinforce stigma, leading to greater concealment and inaccurate reporting (van Poppel \& Day, 1996).

\section{Migrants $(\mathbf{n}=\mathbf{2 0})$}

There is mixed evidence about the influence of migration on suicide. While some research supports the premise that migration is associated with higher suicide rates (Burvill, 1998; Johansson, Sundquist, Johansson, Qvist, \& Bergman, 1997; Stack, 1981; Stack, 2000b; Whitley, Gunnell, Dorling, \& Smith, 1999), this relationship appears to be contingent on individual factors related to the migrant and their country of origin (Ferrada-Noli, 2007; Hjern, Lindblad, \& Vinnerljung, 2002; Johansson, Sundquist, Johansson, Bergman, et al., 1997; Kliewer, 1991; Voracek \& Loibl, 2008; Westman, Sundquist, Johansson, Johansson, \& Sundquist, 2006). Migrant suicide is also likely to be influenced by ethnicity, gender, age, socioeconomic status and residence in urban or rural area of residence of the host country (Kliewer \& Ward, 1988; Morrell, Taylor, Slaytor, \& Ford, 1999; Shah, Lindesay, \& Dennis, 2009; Singh \& Siahpush, 2006; Taylor, Morrell, Slaytor, \& Ford, 1998; Trovato \& Jarvis, 1986). Factors such as shorter duration of residence (Hjern \& Allebeck, 2002) and relationship status (i.e., single immigrants may have higher risk) (Kposowa, McElvain, \& Breault, 2008) could also have an influence on migrant suicide rates. A study by Ott and colleagues (Ott, Winkler, Kyobutungi, Laki, \& Becher, 2008) also suggests that second generation immigrants are at greater risk of suicide than their parental generation.

\section{Rural Locations (n = 26)}

Studies from a number of different cultural contexts report that those living in rural areas are more at risk of suicide than those living in urban areas (Dudley, Kelk, Florio, Howard, \& Waters, 1998; Gartner, Farewell, Roach, \& Dunstan, 2011; Hempstead, 2006; Kapusta et al., 2008; Kim, Jung-Choi, Jun, \& Kawachi, 2010; Phillips, 2009; Singh \& Siahpush, 2002; Yip, Callanan, \& Yuen, 2000). For example, research in Australia and New Zealand suggests that younger and older males in rural areas have higher suicide rates than their metropolitan counterparts (Caldwell, Jorm, \& Dear, 2004; Dudley et al., 1998; Morrell et al., 1999; Yip et al., 2000), while older adults and females are reported as being more "at risk" in rural areas of Asia (Liu, Tein, Zhao, \& Sandler, 2005; Phillips, Li, \& Zhang, 2002; Pritchard, 1996; Yip et al., 2000). There are a number of explanations for these geographical differences, some of which focus on exposure to risk factors (e.g. drugs and alcohol abuse), prevalence of treatment and support services (e.g. availability of mental health services), and access to lethal suicide methods (Caldwell et al., 2004; Hempstead, 2006; Hirsch, 2006; Judd, Cooper, Fraser, \& Davis, 2006; Klieve, Barnes, \& De Leo, 2009; Klieve, Sveticic, \& De Leo, 2009; Konradsen, Hoek, \& Peiris, 2006; Konradsen et al., 2003; Roberts et al., 2003; Saunderson, Haynes, \& Langford, 1998). Other researchers focus on the role of cultural norms in rural and urban areas, and the importance of values and relationships in the surrounding psycho-social environment (Alston, 2010;
Baller \& Richardson, 2002; Dudley et al., 1998; Hirsch, 2006; Pritchard, 1996). The relationship between rural residence and suicide has also been found to be sensitive to societal change, as studies have reported changes in the rural-urban suicide ratio over time (Chang, Gunnell, Wheeler, Yip, \& Sterne, 2010; Kapusta et al., 2008; Page, Morrell, Taylor, Dudley, \& Carter, 2007; Pearce, Barnett, \& Jones, 2007).

\section{Modernisation $(\mathbf{n}=\mathbf{8})$}

Durkheim's (1897) research investigated the influence of modernisation (conceptualised as the process of industrialisation, urbanisation and secularisation) on suicide rates in European nations in the late 1800s. According to Durkheim, the changes modernisation brought to society disrupted regulatory mechanisms and the social and community bonds that protected against suicide: “every disturbance of equilibrium, even though it may involve greater comfort and a raising of the general pace of life, provides an impulse to voluntary death" (Durkheim, 1897: pp. 206-207). More recent studies on the relationship between modernisation and suicide rates have produced different results (Stack, 2000b). Stack (2000b) presents two possible reasons for this. Firstly, he argues that after the "initial shocks" of modernisation have passed, suicide rates in society will cease to be sensitive to this process. Secondly, the high degree of correlation between indicators traditionally used as proxies for modernisation creates methodological complications.

Several recent approaches have attempted to address these limitations by modifying the concept to include variables that may better reflect contemporary societies. For example, Fernquist and Cutright (1998) used indicators such as telephone lines per 100 persons and tertiary education enrolments to provide an updated understanding of modernisation in developed nations. A study by Vijayakumar and colleagues (2005) provides another perspective on this topic. These researchers found that countries with a medium "human development index" (an aggregate measure of human development in terms of life expectancy, literacy, and income) had lower suicide rates. Zhang (1998) measures modernisation through variables such as birth rate and age distribution of the population, life-expectancy, urbanisation, percentage of married women using contraception, and per capita GNP. An alternative approach is presented by Mäkinen (1997), who measures modernisation through variables such as marriage and divorce, the percentage of births occurring outside marriage, female employment, unemployment, and the ownership of television sets. In 2007, Graeff and Mehlkopf defined modernisation as a "technical form of social change" and measured this through indicators such as intensification of communication processes and size of the government (implying the effect of the government on social welfare). Most recently, a study using an aggregate measure of globalisation found that this was associated with higher suicide rates in 35 areas of the world (Milner et al., 2011). However, it is worth noting that the studies presented above deviate from the original concept of modernisation described by Durkheim (1897).

\section{Media Reporting of Suicide $(\mathbf{n}=19)$}

Media guidelines for the reporting of suicide are commonly included in national intervention efforts because of the concern that insensitive descriptions may result in an increase in suicide deaths (Cheng, Hawton, Lee, \& Chen, 2007; Fu \& Yip, 2007; Pirkis, Blood, Beautrais, Burgess, \& Skehans, 2006; Stack, 
2009). There is some evidence to support this perspective, as recent research papers identify an increase in suicide rates after damaging media reports (Chen et al., 2010; Chen, Chen, \& Yip, 2011; Fu, Chan, \& Yip, 2011; Gould, 2001; Hagihara, Tarumi, \& Abe, 2007; Niederkrotenthaler \& Sonneck, 2007; Pirkis \& Blood, 2001a, 2001b; Stack, 2005; Sudak \& Sudak, 2005; Tsai \& Cho, 2011). This relationship appears to be stronger for factual media reports (Cheng, Hawton, Chen et al., 2007; Cheng, Hawton, Lee et al., 2007; Niederkrotenthaler et al., 2009; Pirkis \& Blood, 2001a; Yip et al., 2006) than for fictional reports of suicide (e.g. films, television, music etc.) (Pirkis \& Blood, 2001b). Further, a meta-analysis of 55 studies on non-fictional accounts found that stories related to entertainment or political suicides were more often associated with a rise in suicide (Stack, 2005). This review also found substantially more imitative effects for female suicide rates than male rates, and less likelihood of imitative effects in younger or middle aged groups. The association between media reporting and suicide is also dependent on the length of time between the occurrence of the suicide and publishing of the story, the number of media sources covering the event, and the specific characteristics of case (Pirkis et al., 2006). Recent research by Niederkrotenthaler and colleagues (2010) reports that printed media articles that focused on specific suicide deaths and "myths" of suicide had a detrimental effect, while those articles on coping behaviours and suicide ideation (not accompanied by suicidal behaviours) were not associated with an increase in suicide. Niederkrotenthaler and Sonneck (2007) also reported that implementing media guidelines was related to more appropriate media reporting of suicide and reduced suicide rates. The mode of coverage is also likely to be important, with television stories being less conducive to imitative effects than newspaper stories (Stack, 2005).

\section{Alcohol $(\mathbf{n}=\mathbf{1 7})$}

Alcohol has been linked to increased country-level suicide rates in Europe, Canada (Hintikka et al., 1999; Inelmen, Gazerro, Inelmen, Sergi, \& Manzato, 2010; Landberg, 2008; Mann, Zalcman, Smart, Rush, \& Suurvali, 2006; Ramstedt, 2001) and in Japan (Nakaya et al., 2007). Alcohol is also thought to be associated with higher rates of suicide in some Indigenous groups and in the Pacific, although empirical data on this relationship is scarce (De Leo, Milner, \& Sveticic, 2012; Laliberté \& Tousignant, 2009; Rubinstein, 1992). At a social level, these associations may vary depending on gender, the prevalence and type of alcohol available, and the attitude toward alcohol consumption in society (Bloomfield, Stockwell, Gmel, \& Rehn, 2003; Kuendig et al., 2008; Landberg, 2008, 2009; Norström \& Skog, 2001; Peele, 1997; Rossow, 1996). For example, the relationship between suicide and alcohol consumption per capita appears to be more noticeable in countries where spirit consumption is high (such as those in Eastern Europe), compared to countries with moderate drinking practices (Inelmen et al., 2010; Landberg, 2008; Pridemore, 2006; Stickley, Jukkala, \& Norstrom, 2011). These findings indicate the importance of considering the national cultural attitude toward alcohol, as well as the actual prevalence of alcohol in a country.

\section{Access to Suicide Methods $(\mathrm{n}=\mathbf{2 1})$}

In western countries, a large number of suicide deaths occur by hanging, while pesticide poisoning is a major cause of death in Asia and Latin America (Ajdacic-Gross et al., 2008; Konradsen et al., 2006; Konradsen et al., 2003; Mohamed et al., 2009; Roberts et al., 2003). There are also noticeable gender differences in the use of suicide methods in many countries, with females more likely to overdose on drugs or poisons, while men tend to use methods such as hanging and firearms (Hawton, Fagg, Simkin, Harriss, \& Malmberg, 1998; Payne, Swami, \& Stanistreet, 2008). It is likely that these differences reflect both cultural and social attitudes towards specific method choice, as well as more pragmatic considerations about the availability of methods (Kanchan, Menon, \& Menezes, 2009; Lin, Chang, \& Lu, 2010).

Reducing access to commonly used methods (e.g. tighter regulation and access to firearms, illegal and legal drugs, agricultural pesticides and domestic gas) has been associated with lower suicide within some populations (Beautrais, Fergusson, \& Horwood, 2005; Daigle, 2005; Hawton, 2007; Nordentoft, Qin, Helweg-Larsen, \& Juel, 2006, 2007; Rodríguez Andrés \& Hempstead, 2011; Skegg \& Herbison, 2009; Wong, Chan, Lau, Morgan, \& Yip, 2009). However, research also suggests the importance of considering the risk of method substitution (whereby suicidal persons prevented from using one method will shift consideration to an alternate method) and the other possible influences such as the degree of familiarity with the method, gender, age and geographical location (De Leo, Dwyer, Firman, \& Neulinger, 2003; De Leo, Evans, \& Neulinger, 2002; Klieve, Barnes et al., 2009; Klieve, Sveticic et al., 2009; Roberts et al., 2003).

\section{Discussion}

This review covered an extensive number of studies, all of which used different approaches and methodologies to examine the relationship between social-environmental factors and suicide mortality. The outcomes of the review indicate that suicide is influenced by a wide range of factors such as income (national income, income per capita), employment trends (unemployment and female labour force participation), family bonds and relationships (fertility, relationship status), religion, location of residence, media reporting of suicide, access to alcohol in society, and lethal means used to suicide. The loss of a spouse (either through divorce or widowhood) appears to be associated with an increase in suicide rates, while female workforce participation, fertility/birth rates, and religion appear to vary over time and between contexts.

As a methodological comment, the research discussed in this paper was conducted using different designs at both the aggregate and individual level. Numerous studies used ecological designs (e.g., Babones, 2008; Berk et al., 2006; Brainerd, 2001; Chang et al., 2009; Chuang \& Huang, 2007; Durkheim, 1897; Hintikka et al., 1999; Milner, McClure et al., 2012; Milner et al., 2011; Milner, Page et al., 2012) either measured over time while fewer used cohort designs (Lundin et al., 2010; Mäki \& Martikainen, 2009; Pritchard, 1992; Qin et al., 2003; Qin et al., 2000). The rationale for using ecological designs as they are able to measure social phenomena or states in relation to death in a population, while cohort studies can control for possible individual confounding factors, such as education or occupation.

Various limitations may have influenced the findings of this review. First, the holistic nature of it means that our review did not discuss methodological or analytic aspects of research arti- 
cles. However, the aim of this paper was to provide an overview of the general findings on these topics rather than providing specific detailed information on a topic. Indeed, each on the topics discussed in this paper could be (and potentially should be) the topic of a whole other paper. Another limitation is that the review did not distinguish between compositional (e.g. the characteristics of individuals concentrated within particular places) or contextual effects (e.g. factors in the local physical or social environment) (Macintyre, Ellaway, \& Cummins, 2002). As we focused only on suicide mortality, it is not possible to generalise the outcomes of this review to non-fatal suicidal behaviours. There are also limitations concerning the design of the study and a number of relevant research papers may have been missed due to the selection of search terms or databases used. Further, the search strategy was skewed towards research from high-income areas due to lack of published data from low-income areas of the world (Bertolote, Fleischmann, De Leo, \& Wasserman, 2004).

Another issue was the continued reliance on material published from before the year 2000. This may have reflected differences in research interest over time. For example, there has been relatively little attention to the topic of gender role change in recent years, while topics like media reporting or unemployment have been the focus of a number of recent research articles. It is also necessary to note that investigation into some social factors, such as economic change, have a longer history of research than others.

The dynamic relationship between social-environmental factors and suicide indicates the importance of longitudinal and contextually specific studies able to identify time intervals at which the relationship between social variables and suicide is most salient. These findings can also be important for suicide prevention. For example, research on "acute" points during which unemployment, migration or divorce are associated with the greatest likelihood of suicide may be able to inform risk assessment and the development of targeted population-level interventions. Research by Stuckler, Basu, Suhrcke, Coutts and McKee (2009) provide evidence of the public health effects of economic crises, in particular in terms of increasing suicide rates. The authors underline the importance of active labour market programs (e.g., those that keep and reintegrate workers in jobs) in mitigating some adverse health effects of economic downturns.

The high suicide risk among people living in rural areas underlines the need to invest in prevention programs specifically targeting rural areas, such as those aimed at improving the skills of the general population in order to manage mental health emergencies including suicidal behaviour (Ellis \& Philip, 2010). However, in general, evidence suggests that reductions in suicide of a population can be achieved through programs containing multiple levels of intervention and which target several at-risk groups (Hegerl, Althaus, Schmidtke, \& Niklewski, 2006).

\section{Conclusion}

Social and environmental contexts present a range of possible and heterogeneous influences on suicide mortality. This review covered recent research about a wide range of factors including income (national income, income per capita), employment trends (unemployment and female labour force participation), family bonds and relationships (fertility and rela- tionship status), religion, location of residence, media reporting of suicide, access to alcohol in society, and lethal means used to suicide. The strength and direction of some of these associations (e.g., female labour force participation, fertility and religion) appear to vary over time and between contexts. The influence of other factors such as relationship status and unemployment appear to be comparatively more stable. Aside from being of interest to social researchers, the findings of this review could be of relevance to policy develop as they highlight the importance of social-environmental factors as protective and risk factor for suicide mortality across population.

\section{REFERENCES}

Abe, R., Shiriri, T., Nishinura, A., Nushida, H., Ueno, Y., Kojima, M., Kitamura, H., Akazawa, K., \& Someya, T. (2004). Economic slump and suicide method: Preliminary study in Kobe. Psychiatry and Clinical Neuroscience, 58, 213-216.

doi:10.1111/j.1440-1819.2003.01219.x

Agerbo, E. (2003). Unemployment and suicide. Journal of Epidemiology and Community Health, 57, 560-561. doi:10.1136/jech.57.8.560

Ajdacic-Gross, V., Gadola, E., Lauber, C., Bopp, M., Gutzwiller, F., \& Rossler, W. (2007). Being widowed-A high risk period for suicide. European Psychiatry, 22, S146. doi:10.1016/j.eurpsy.2007.01.471

Ajdacic-Gross, V., Weiss, M. G., Ring, M., Hepp, U., Bopp, M., Gutzwiller, F., \& Rössler, W. (2008). Methods of suicide: International suicide patterns derived from the WHO mortality database. Bulletin of the World Health Organization, 86, 726-732. doi:10.2471/BLT.07.043489

Aliverdinia, A., \& Pridemore, W. A. (2009). Women's fatalistic suicide in Iran: A partial test of Durkheim in an Islamic Republic. Violence Against Women, 15, 307-320. doi:10.1177/1077801208330434

Alston, M. (2010). Rural male suicide in Australia. Social Science \& Medicine, 74, 515-522. doi:10.1016/j.socscimed.2010.04.036

Andres, A. R., \& Halicioglu, F. (2010). Determinants of suicides in Denmark: Evidence from time series data. Health Policy, 98, 263269. doi:10.1016/j.healthpol.2010.06.023

Austin, R. L., Bologna, M., \& Hayama Dodge, H. (1992). Sex-role change, anomie, and female suicide: A test of alternative Durkheimian explanations. Suicide \& Life-Threatening Behavior, 22, 197225.

Babones, S. J. (2008). Income inequality and population health: Correlation and causality. Social Science \& Medicine, 66, 1614-1626. doi:10.1016/j.socscimed.2007.12.012

Baller, R. D., Levchak, P., \& Schultz, M. (2010). "The great transformation" and suicide: Local and long-lasting effects of 1930 bank suspensions. Suicide \& Life-Threatening Behavior, 40, 574-586. doi:10.1521/suli.2010.40.6.574

Baller, R. D., \& Richardson, K. K. (2002). Social integration, imitation, and the geographic patterning of suicide. American Sociological Review, 67, 873-888. doi:10.2307/3088974

Barstad, A. (2008). Explaining changing suicide rates in Norway 1948-2004: The role of social integration. Social Indicators Research, 87, 47-64. doi:10.1007/s11205-007-9155-X

Beautrais, A. L., Fergusson, D. M., \& Horwood, L. J. (2005). Firearms legislation and reductions in firearm-related suicide deaths in New Zealand. Australian and New Zealand Journal of Psychiatry, 40, 253-259. doi:10.1080/j.1440-1614.2006.01782.x

Berk, M., Dodd, S., \& Henry, M. (2006). The effect of macroeconomic variables on suicide. Psychological Medicine, 36, 181-189. doi:10.1017/S0033291705006665

Bertolote, J. M., Fleischmann, A., De Leo, D., \& Wasserman, D. (2004). Psychiatric diagnoses and suicide: Revisiting the evidence. Crisis: The Journal of Crisis Intervention and Suicide Prevention, 25, 147155. doi:10.1027/0227-5910.25.4.147

Bhandarkar, R., \& Shah, A. (2008). Association of general population suicide rates with fertility rates: A test of fertility as a measure of so- 
cial integration. Psychological Reports, 103, 812-818.

doi:10.2466/pr0.103.3.812-818

Blakely, T., Collings, S. C. D., \& Atkinson, J. (2003). Unemployment and suicide. Evidence for a causal association? Journal of Epidemiology and Community Health, 57, 594-600. doi:10.1136/jech.57.8.594

Bloomfield, K., Stockwell, T., Gmel, G., \& Rehn, N. (2003). International comparisons of alcohol consumption. Alcohol Research \& Health, 27, 95-110.

Brainerd, E. (2001). Economic reform and mortality in the former Soviet Union: A study of the suicide epidemic in the 1990s. European Economic Review, 45, 1007-1019. doi:10.1016/S0014-2921(01)00108-8

Burr, J. A., McCall, P. L., \& Powell-Griner, E. (1997). Female labor force participation and suicide. Social Science \& Medicine, 44, 18471859. doi:10.1016/S0277-9536(96)00294-8

Burvill, P. W. (1998). Migrant suicide rates in Australia and in country of birth. Psychological Medicine, 28, 201-208. doi:10.1017/S0033291797005850

Caldwell, T. M., Jorm, A. F., \& Dear, K. B. (2004). Suicide and mental health in rural, remote and metropolitan areas in Australia. Medical Journal of Australia, 181, S10-S14.

Chan, W. S., Yip, P. S., Wong, P. W., \& Chen, E. Y. (2007). Suicide and unemployment: What are the missing links? Archives of Suicide Research, 11, 327-335. doi:10.1080/13811110701541905

Chang, S.-S., Gunnell, D., Wheeler, B. W., Yip, P., \& Sterne, J. A. C. (2010). The evolution of the epidemic of charcoal-burning suicide in Taiwan: A spatial and temporal analysis. PLoS Medicine, 7, e1000212. doi:10.1371/journal.pmed.1000212

Chang, S. S., Gunnell, D., Sterne, J. A., Lu, T. H., \& Cheng, A. T. (2009). Was the economic crisis 1997-1998 responsible for rising suicide rates in East/Southeast Asia? A time-trend analysis for Japan, Hong Kong, South Korea, Taiwan, Singapore and Thailand. Social Science \& Medicine, 68, 1322-1331.

doi:10.1016/j.socscimed.2009.01.010

Chang, S. S., Sterne, J. A., Wheeler, B. W., Lu, T. H., Lin, J. J., \& Gunnell, D. (2011). Geography of suicide in Taiwan: Spatial patterning and socioeconomic correlates. Health and Place, 17, 641-650. doi:10.1016/j.healthplace.2011.01.003

Chang, S. S., Sterne, J. A. C., Huang, W. C., Chuang, H. L., \& Gunnell, D. (2010). Association of secular trends in unemployment with suicide in Taiwan, 1959-2007: A time-series analysis. Public Health, 124, 49-54. doi:10.1016/j.puhe.2009.11.005

Chen, Y.-Y., Yip, P. S., Lee, C., Fan, H.-F., \& Fu, K.-W. (2010). Economic fluctuations and suicide: A comparison of Taiwan and Hong Kong. Social Science and Medicine, 71, 2083-2090. doi:10.1016/j.socscimed.2010.09.043

Chen, Y. Y., Chen, F., \& Yip, P. S. (2011). The impact of media reporting of suicide on actual suicides in Taiwan, 2002-05. Journal of Epidemiology and Community Health, 65, 934-940. doi:10.1136/jech.2010.117903

Cheng, A. T., Hawton, K., Chen, T. H., Yen, A. M., Chang, J. C., Chong, M. Y., et al. (2007). The influence of media reporting of a celebrity suicide on suicidal behavior in patients with a history of depressive disorder. Journal of Affective Disorders, 103, 69-75. doi:10.1016/j.jad.2007.01.021

Cheng, A. T., Hawton, K., Lee, C. T., \& Chen, T. H. (2007). The influence of media reporting of the suicide of a celebrity on suicide rates: A population-based study. International Journal of Epidemiology, 36, 1229-1234. doi:10.1093/ije/dym196

Chuang, H.-L., \& Huang, W.-C. (2007). A re-examination of the suicide rates in Taiwan. Social Indicators Research, 83, 465-485.

Clarke, C. S., Bannon, F. J., \& Denihan, A. (2003). Suicide and religiosity-Masaryk's theory revisited. Social Psychiatry and Psychiatric Epidemiology, 38, 502-506. doi:10.1007/s00127-003-0668-6

Cleary, A., \& Brannick, T. (2007). Suicide and changing values and beliefs in Ireland. Crisis: The Journal of Crisis Intervention and Suicide Prevention, 28, 82-88. doi:10.1027/0227-5910.28.2.82

Colucci, E., \& Martin, G. (2008). Religion and spirituality along the suicidal path. Suicide \& Life-Threatening Behavior, 38, 229-244. doi:10.1521/suli.2008.38.2.229

Corcoran, P. (2009). The impact of widowhood on Irish mortality due to suicide and accidents. European Journal of Public Health, 19, 583-585. doi:10.1093/eurpub/ckp166

Corcoran, P., \& Arensman, E. (2011). Suicide and employment status during Ireland's Celtic Tiger economy. The European Journal of Public Health, 21, 209-214. doi:10.1093/eurpub/ckp236

Corcoran, P., \& Nagar, A. (2010). Suicide and marital status in Northern Ireland. Social Psychiatry and Psychiatric Epidemiology, 45, 795-800. doi:10.1007/s00127-009-0120-7

Crawford, M. J., \& Prince, M. (1999). Increasing rates of suicide in young men in England during the 1980s: The importance of social context. Social Science \& Medicine, 49, 1419-1423.

doi:10.1016/S0277-9536(99)00213-0

Cutright, P., \& Fernquist, R. M. (2001a). Effects of societal integration, period, region, and culture of suicide on male age-specific suicide rates: 20 developed countries, 1955-1989. Social Science Research, 29, 148-172. doi:10.1006/ssre.1999.0658

Cutright, P., \& Fernquist, R. M. (2001b). The relative gender gap in suicide: Societal integration, the culture of suicide, and period effects in 20 developed countries, 1955-1994. Social Science Research, 30, 76-99. doi:10.1006/ssre.2000.0691

Cutright, P., \& Fernquist, R. M. (2004). The culture of suicide through societal integration and religion: 1996-1998 gender-specific suicide rates in 50 American states. Archives of Suicide Research, 8, 271285. doi:10.1080/13811110490436936

Cutright, P., \& Fernquist, R. M. (2007). Three explanations of marital status differences in suicide rates: Social integration, marital status integration, and the culture of suicide. Omega: Journal of Death and Dying, 56, 175-190. doi:10.2190/OM.56.2.c

Cutright, P., Stack, S., \& Ferquist, R. (2007). Marital status integration, suicide disapproval, and societal integration as explanations of marital status differences in female age-specific suicide rates. Suicide \& Life-Threatening Behavior, 37, 715-724. doi:10.1521/suli.2007.37.6.715

Daigle, M. S. (2005). Suicide prevention through means restriction: Assessing the risk of substitution-A critical review and synthesis. Accident Analysis and Prevention, 37, 625-632. doi:10.1016/j.aap.2005.03.004

Daly, M. C., \& Wilson, D. J. (2009). Happiness, unhappiness and suicide: An empirical assessment. Journal of the European Economic Association, 7, 539-549. doi:10.1162/JEEA.2009.7.2-3.539

Davis, R. A. (1981). Female labor force participation, status integration and suicide, 1950-1969. Suicide \& Life-Threatening Behavior, 11, 111-123.

De Leo, D., Dwyer, J., Firman, D., \& Neulinger, K. (2003). Trends in hanging and firearm suicide rates in Australia: Substitution of method? Suicide \& Life-Threatening Behavior, 33, 151-164. doi:10.1521/suli.33.2.151.22775

De Leo, D., Evans, R., \& Neulinger, K. (2002). Hanging, firearm, and non-domestic gas suicides among males: A comparative study. Australian and New Zealand Journal of Psychiatry, 36, 183-189. doi:10.1046/j.1440-1614.2001.01013.x

De Leo, D., Milner, A., \& Sveticic, J. (2012). Mental disorders and communication of intent to die in suicide cases of Indigenous people of Queensland, Australia. Suicide \& Life-Threatening Behavior, 42, 136-146. doi:10.1111/j.1943-278X.2011.00077.x

De Vogli, R., \& Gimeno, D. (2009). Changes in income inequality and suicide rates after "shock therapy": Evidence from Eastern Europe. Journal of Epidemiology and Community Health, 63, 956. doi:10.1136/jech.2008.084079

Denney, J. T., Rogers, R. G., Krueger, P. M., \& Wadsworth, T. (2009). Adult suicide mortality in the United States: Marital status, family size, socioeconomic status, and differences by sex. Social Science Quarterly, 90, 1167-1185. doi:10.1111/j.1540-6237.2009.00652.X

Dudley, M. J., Kelk, N. J., Florio, T. M., Howard, J. P., \& Waters, B. G. H. (1998). Suicide among young Australians, 1964-1993: An interstate comparison of metropolitan and rural trends. Medical Journal of Australia, 169, 77-80.

Durkheim, E. (1897). Suicide, a study in sociology (1951 Edition, J. A. 
Spaulding, \& G. Simpson, Trans.). London: Routledge.

Easterlin, R. A. (1974). Does economic growth improve the human lot? In P. A. David, \& M. W. Reder (Eds.), Nations and Households in Economic Growth: Essays in Honour of Moses Abramovitz (pp. 89-125). New York: Academic Press Inc.

Ellis, I. K., \& Philip, T. (2010). Improving the skills of rural and remote generalists to manage mental health emergencies. Rural and Remote Health, 10, 1503.

Ellison, C. G., Burr, J. A., \& McCall, P. L. (1997). Religious homogeneity and metropolitan suicide rates. Social Forces, 76, 273-299.

Faria, N. M., Victora, C. G., Meneghel, S. N., De Carvalho, L. A., \& Falk, J. W. (2006). Suicide rates in the State of Rio Grande do Sul, Brazil: Association with socioeconomic, cultural, and agricultural factors. Cadernos de Saúde Pública, 22, 2611-2621. doi:10.1590/S0102-311X2006001200011

Fernquist, R. M. (1999). Gender equality and the sex differential in suicide rates using gender-age standardized data. Archives of Suicide Research, 5, 255-260. doi:10.1080/13811119908258336

Fernquist, R. M. (2003). Percieved income inequality and suicide rates in Central/Eastern European countries and Western countries, 1990-1993. Death Studies, 27, 63-80. doi:10.1080/07481180302870

Fernquist, R. M. (2007). How do Durkheimian variables impact variation in National suicide rates when proxies for depression and alcoholism are controlled? Archives of Suicide Research, 11, 361-374. doi:10.1080/13811110600897226

Fernquist, R. M., \& Cutright, P. (1998). Societal integration and age-standardized suicide rates in 21 developed countries, 1955-1989. Social Science and Research, 27, 109-127. doi:10.1006/ssre.1998.0615

Ferrada-Noli, M. (2007). A cross-cultural breakdown of Swedish suicide. Acta Psychiatrica Scandinavica, 96, 108-116. doi:10.1111/j.1600-0447.1997.tb09914.x

Fu, K. W., Chan, Y. Y., \& Yip, P. S. (2011). Newspaper reporting of suicides in Hong Kong, Taiwan and Guangzhou: Compliance with WHO media guidelines and epidemiological comparisons. Journal of Epidemiology \& Community Health, 65, 928-933. doi:10.1136/jech.2009.105650

Fu, K. W., \& Yip, P. S. (2007). Long-term impact of celebrity suicide on suicidal ideation: Results from a population-based study. Journal of Epidemiological and Community Health, 61, 540-546. doi:10.1136/jech.2005.045005

Gartner, A., Farewell, D., Roach, P., \& Dunstan, F. (2011). Rural/urban mortality differences in England and Wales and the effect of deprivation adjustment. Social Science \& Medicine, 72, 1685-1694. doi:10.1016/j.socscimed.2011.03.017

Gearing, R. E., \& Lizardi, D. (2009). Religion and suicide. Journal of Religion and Health, 48, 332-341. doi:10.1007/s10943-008-9181-2

Gould, M. S. (2001). Suicide and the media. Annals of the New York Academy of Sciences, 932, 200-221.

Graeff, P., \& Mehlkop, G. (2007). When anomie becomes a reason for suicide: A new macro-sociological approach in the durkheimian tradition. European Sociological Review, 23, 521-535. doi:10.1093/esr/jcm020

Graham, C., \& Pettinato, S. (2002). Frustrated Achievers: Winners, Losers and subjective well-being in new market economies. Journal of Development Studies, 38, 100-140. doi:10.1080/00220380412331322431

Griffiths, C., Ladva, G., Brock, A., \& Baker, A. (2008). Trends in suicide by marital status in England and Wales, 1982-2005. Health Statistics Quarterly, 37, 8-14.

Gunnell, D., Middleton, N., Whitley, E., Dorling, D., \& Frankel, S. (2003). Why are suicide rates rising in young men but falling in the elderly? A time-series analysis of trends in England and Wales 1950-1998. Social Science \& Medicine, 57, 595-611. doi:10.1016/S0277-9536(02)00408-2

Hagihara, A., Tarumi, K., \& Abe, T. (2007). Media suicide-reports, internet use and the occurrence of suicides between 1987 and 2005 in Japan. BMC Public Health, 7, 321. doi:10.1186/1471-2458-7-321

Hawton, K. (2007). Restricting access to methods of suicide: Rationale and evaluation of this approach to suicide prevention. Crisis: The Journal of Crisis Intervention and Suicide Prevention, 28, 4-9. doi:10.1027/0227-5910.28.S1.4

Hawton, K., Fagg, J., Simkin, S., Harriss, L., \& Malmberg, A. (1998). Methods used for suicide by farmers in England and Wales. The contribution of availability and its relevance to prevention. British Journal of Psychiatry, 173, 320-324. doi:10.1192/bjp.173.4.320

Hegerl, U., Althaus, D., Schmidtke, A., \& Niklewski, G. (2006). The alliance against depression: 2-year evaluation of a community-based intervention to reduce suicidality. Psychological Medicine, 36, 1225 1233. doi:10.1017/S003329170600780X

Helliwell, J. F. (2007). Well-being and social capital: Does suicide pose a puzzle? Social Indicators Research, 81, 455-496. doi:10.1007/s11205-006-0022-y

Hempstead, K. (2006). The geography of self-injury: Spatial patterns in attempted and completed suicide. Social Science \& Medicine, 62, 3186-3196. doi:10.1016/j.socscimed.2005.11.038

Hintikka, J., Saarinen, P. I., \& Viinamaki, H. (1999). Suicide mortality in Finland during an economic cycle, 1985-1995. Scandinavian Journal of Public Health, 27, 85-88. doi:10.1177/14034948990270020601

Hirsch, J. K. (2006). Review of the literature on rural suicide: Risk and protective factors, incidence, and prevention. Crisis: The Journal of Crisis Intervention and Suicide Prevention, 27, 189-199. doi:10.1027/0227-5910.27.4.189

Hjern, A., \& Allebeck, P. (2002). Suicide in first- and second-generation immigrants in Sweden: A comparative study. Social Psychiatry \& Psychiatric Epidemiology, 37, 423-429. doi:10.1007/s00127-002-0564-5

Hjern, A., Lindblad, F., \& Vinnerljung, B. (2002). Suicide, psychiatric illness, and social maladjustment in intercountry adoptees in Sweden: A cohort study. The Lancet, 360, 443-448.

doi:10.1016/S0140-6736(02)09674-5

Ide, N., Wyder, M., Kolves, K., \& De Leo, D. (2011). Separation as an important risk factor for suicide: A systematic review. Journal of Family Issues, 31, 1689-1716. doi:10.1177/0192513X10365317

Inagaki, K. (2010). Income inequality and the suicide rate in Japan: Evidence from cointegration and LA-VAR. Journal of Applied Economics, 13, 113-133. doi:10.1016/S1514-0326(10)60006-2

Inelmen, E. M., Gazerro, M., Inelmen, E., Sergi, G., \& Manzato, E. (2010). Alcohol consumption and suicide: A country-level study. Italian Journal of Public Health, 7, 226-234.

Jin, R. (1995). The impact of unemployment on health: A review of the evidence. Canadian Medical Association Journal, 153, 1567-1568.

Johansson, L. M., Sundquist, J., Johansson, S. E., Bergman, B., Qvist, J., \& TraskmanBendz, L. (1997). Suicide among foreign-born minorities and native Swedes: An epidemiological follow-up study of a defined population. Social Science \& Medicine, 44, 181-187. doi:10.1016/S0277-9536(96)00142-6

Johansson, L. M., Sundquist, J., Johansson, S. E., Qvist, J., \& Bergman, B. (1997). The influence of ethnicity and social and demographic factors on Swedish suicide rates-A four year follow-up study. Social Psychiatry \& Psychiatric Epidemiology, 32, 165-170.

Judd, F., Cooper, A. M., Fraser, C., \& Davis, J. (2006). Rural suicidePeople or place effects? Australian and New Zealand Journal of Psychiatry, 40, 208-216.

Kanchan, T., Menon, A., \& Menezes, R. G. (2009). Methods of choice in completed suicides: Gender differences and review of literature. Journal of Forensic Sciences, 54, 938-942. doi:10.1111/j.1556-4029.2009.01054.x

Kapusta, N., Zorman, A., Etzersdorfer, E., Ponocny-Seliger, E., JandlJager, E., \& Sonneck, G. (2008). Rural-urban differences in Austrian suicides. Social Psychiatry and Psychiatric Epidemiology, 43, 311318. doi:10.1007/s00127-008-0317-1

Kawachi, I., Kennedy, B. P., Lochner, K., \& Prothrow-Smith, D. (1997). Social capital, inequality and mortality. American Journal of Public Health, 87, 1491-1498. doi:10.2105/AJPH.87.9.1491

Khang, Y.-H., Lynch, J. W., \& Kaplan, G. A. (2005). Impact of economic crisis on cause-specific mortality in South Korea. International Journal of Epidemiology, 34, 1291-1301. 
Kim, M. H., Jung-Choi, K., Jun, H. J., \& Kawachi, I. (2010). Socioeconomic inequalities in suicidal ideation, parasuicides, and completed suicides in South Korea. Social Science \& Medicine, 70, 12541261. doi:10.1016/j.socscimed.2010.01.004

King, L., Hamm, P., \& Stuckler, D. (2009). Rapid large-scale privatization and death rates in ex-communist countries: An analysis of stress-related and health system mechanisms. International Journal of Health Services, 39, 461-489. doi:10.2190/HS.39.3.c

Klieve, H., Barnes, M., \& De Leo, D. (2009). Controlling firearms use in Australia: Has the 1996 gun law reform produced the decrease in rates of suicide with this method? Social Psychiatry \& Psychiatric Epidemiology, 44, 285-292. doi:10.1007/s00127-008-0435-9

Klieve, H., Sveticic, J., \& De Leo, D. (2009). Who uses firearms as a means of suicide? A population study exploring firearm accessibility and method choice. BMC Medicine, 7, 52. doi:10.1186/1741-7015-7-52

Kliewer, E. (1991). Immigrant suicide in Australia, Canada, England and Wales, and the United States. Journal of Population Research, 8, 111-128.

Kliewer, E. V., \& Ward, R. H. (1988). Convergence of immigrant suicide rates to those in the destination country. American Journal of Epidemiology, 127, 640-653.

Konradsen, F., Hoek, W., \& Peiris, P. (2006). Reaching for the bottle of pesticide-A cry for help. Self-inflicted poisonings in Sri Lanka. Social Science \& Medicine, 62, 1710-1719.

doi:10.1016/j.socscimed.2005.08.020

Konradsen, F., Van der Hoek, W., Cole, D. C., Hutchinson, G., Daisley, H., Singh, S., \& Eddleston, M. (2003). Reducing acute poisoning in developing countries-Options for restricting the availability of pesticides. Toxicology, 192, 249-261. doi:10.1016/S0300-483X(03)00339-1

Kposowa, A. J. (2000). Marital status and suicide in the national longitudinal mortality study. Journal of Epidemiology \& Community Health, 54, 254-261. doi:10.1136/jech.54.4.254

Kposowa, A. J. (2001). Unemployment and suicide: A cohort analysis of social factors predicting suicide in the US National Longitudinal Mortality Study. Psychological Medicine, 31, 127-138. doi:10.1017/S0033291799002925

Kposowa, A. J., McElvain, J. P., \& Breault, K. D. (2008). Immigration and suicide: The role of marital status, duration of residence, and social integration. Archives of Suicide Research, 12, 82-92. doi:10.1080/13811110701801044

Krupinski, J. (1980). Domestic integration and the rate of suicide: A comparative study. Journal of Comparative Family Studies, 11, 261263.

Kuendig, H., Plant, M., Plant, M., Miller, P., Kuntsche, S., \& Gmel, G. (2008). Alcohol-related adverse consequences: Cross-cultural variations in attribution process among young adults. European Journal of Public Health, 18, 386-391. doi:10.1093/eurpub/ckn007

Kuroki, M. (2010). Suicide and unemployment in Japan: Evidence from municipal level suicide rates and age-specific suicide rates. Journal of Socio-Economics, 39, 683-691. doi:10.1016/j.socec.2010.06.009

Laliberté, A., \& Tousignant, M. (2009). Alcohol and other contextual factors of suicide in four aboriginal communities of Quebec, Canada. Crisis, 30, 215-221. doi:10.1027/0227-5910.30.4.215

Landberg, J. (2008). Alcohol and suicide in eastern Europe. Drug and Alcohol Review, 27, 361-373. doi:10.1080/09595230802093778

Landberg, J. (2009). Per capita alcohol consumption and suicide rates in the US, 1950-2002. Suicide \& Life-Threatening Behavior, 39, 452459. doi:10.1521/suli.2009.39.4.452

Leenaars, A. A., \& Lester, D. (1999). Domestic Integration and Suicide in the Provinces of Canada. Crisis: The Journal of Crisis Intervention and Suicide Prevention, 20, 59-63. doi:10.1027//0227-5910.20.2.59

Leigh, A., \& Jencks, C. (2007). Inequality and mortality: Long-run evidence from a panel of countries. Journal of Health Economics, 26, 1-24. doi:10.1016/j.jhealeco.2006.07.003

Lester, D., \& Yang, B. (1991). The relationship between divorce, unemployment and female participation in the labour force and suicide rates in Australia and America. Australian and New Zealand Journal of Psychiatry, 25, 519-523. doi:10.3109/00048679109064445

Lester, D., \& Yang, B. (1997). The Economy and suicide: Economic perspectives on suicide. Commack, NY: Nova Science Publishers.

Lewis, G., \& Sloggett, A. (1998). Suicide, deprivation, and unemployment: Record linkage study. British Medical Journal, 317, 1283-1286. doi:10.1136/bmj.317.7168.1283

Lin, J.-J., Chang, S.-S., \& Lu, T.-H. (2010). The leading methods of suicide in Taiwan, 2002-2008. BMC Public Health, 10, 480. doi:10.1186/1471-2458-10-480

Lin, S.-J. (2006). Unemployment and suicide: Panel data analyses. The Social Science Journal, 43, 727-732. doi:10.1016/j.soscij.2006.08.013

Liu, X., Tein, J. Y., Zhao, Z., \& Sandler, I. N. (2005). Suicidality and correlates among rural adolescents of China. Journal of Adolescent Health, 37, 443-451. doi:10.1016/j.jadohealth.2004.08.027

Lorant, V., Kunst, A. E., Huisman, M., Costa, G., Mackenbach, J., \& The E. U. Working Group on Socio-Economic Inequalities in Health. (2005). Socio-economic inequalities in suicide: A European comparative study. The British Journal of Psychiatry, 187, 49-54. doi:10.1192/bjp.187.1.49

Lucey, S., Corcoran, P., Keeley, H. S., Brophy, J., Arensman, E., \& Perry, I. J. (2005). Socioeconomic change and suicide: A time-series study from the Republic of Ireland. Crisis, 26, 90-94. doi:10.1027/0227-5910.26.2.90

Lundin, A., Lundberg, I., Hallsten, L., Ottosson, J., \& Hemmingsson, T. (2010). Unemployment and mortality-A longitudinal prospective study on selection and causation in 49321 Swedish middle-aged men. Journal of Epidemiology and Community Health, 64, 22-28. doi:10.1136/jech.2008.079269

Luoma, J. B., \& Pearson, J. L. (2002). Suicide and marital status in the United States, 1991-1996: Is Widowhood a Risk Factor? American Journal of Public Health, 92, 1518-1522. doi:10.2105/AJPH.92.9.1518

Lynch, J., Smith, G. D., Hillemeier, M., Shaw, M., Raghunathan, T., \& Kaplan, G. (2001). Income inequality, the psychosocial environment, and health: Comparisons of wealthy nations. Lancet, 358, 194-200. doi:10.1016/S0140-6736(01)05407-1

Maag, T. (2008). Economic correlates of suicide rates in OECD countries. KOF Working Papers, No 207, KOF Swiss Economic Institute.

Macintyre, S., Ellaway, A., \& Cummins, S. (2002). Place effects on health: How can we conceptualise, operationalise and measure them? Social Science \& Medicine, 55, 125-139. doi:10.1016/S0277-9536(01)00214-3

Mäki, N., \& Martikainen, P. (2009). The role of socioeconomic indicators on non-alcohol and alcohol-associated suicide mortality among women in Finland. A register-based follow-up study of 12 million person-years. Social Science \& Medicine, 68, 2161-2169. doi:10.1016/j.socscimed.2009.04.006

Mäkinen, I. (1997). Are there social correlates to suicide? Social Science \& Medicine, 44, 1919-1929. doi:10.1016/S0277-9536(97)00016-6

Mann, R., Zalcman, R., Smart, R., Rush, B., \& Suurvali, H. (2006). Alcohol consumption, alcoholics anonymous membership, and suicide mortality rates, Ontario, 1968-1991. Journal of Studies on Alcohol and Drugs, 67, 445-453.

Martikainen, P. T., \& Valkonen, T. (1996). Excess mortality of unemployed men and women during a period of rapidly increasing unemployment. The Lancet, 348, 909-912. doi:10.1016/S0140-6736(96)03291-6

Masocco, M., Pompili, M., Vanacore, N., Innamorati, M., Lester, D. Girardi, P., \& Vichi, M. (2010). Completed suicide and marital status according to the Italian region of origin. Psychiatric Quarterly, 81, 57-71. doi:10.1007/s11126-009-9118-2

Masocco, M., Pompili, M., Vichi, M., Vanacore, N., Lester, D., \& Tatarelli, R. (2008). Suicide and marital status in Italy. Psychiatric Quarterly, 79, 275-285. doi:10.1007/s11126-008-9072-4

Messner, S., Bjarnason, T., Raffalovich, L., \& Robinson, B. (2006). Nonmarital fertility and the effects of divorce rates on youth suicide rates. Journal of Marriage and Family, 68, 1105-1111. doi:10.1111/j.1741-3737.2006.00316.x 
Miller, J. R., Piper, T. M., Ahern, J., Tracy, M., Tardiff, K. J., Vlahov, D., \& Sandro, G. (2005). Income inequality and risk of suicide in New York city neighborhoods: A multilevel case-control study. Suicide \& Life-Threatening Behavior, 35, 448-459. doi:10.1521/suli.2005.35.4.448

Milner, A., McClure, R., \& De Leo, D. (2012). Socio-economic determinants of suicide: An ecological analysis of 35 countries. Social Psychiatry \& Psychiatric Epidemiology, 47, 19-27. doi:10.1007/s00127-010-0316-X

Milner, A., McClure, R., Sun, J., \& De Leo, D. (2011). Globalisation and suicide: An empirical investigation in 35 countries over the period 1980-2006. Health and Place, 17, 996-1003.

doi:10.1016/j.healthplace.2011.03.002

Milner, A., Page, A., \& Lamontagne, A. D. (2012). Duration of unemployment and suicide in Australia over the period 1985-2006: An ecological investigation by sex and age during rising versus declining national unemployment rates. Journal of Epidemiology and Community Health, 67, 237-244. doi:10.1136/jech-2012-201594

Mohamed, F., Manuweera, G., Gunnell, D., Azher, S., Eddleston, M., Dawson, A., \& Konradsen, F. (2009). Pattern of pesticide storage before pesticide self-poisoning in rural Sri Lanka. BMC Public Health, 9, 405. doi:10.1186/1471-2458-9-405

Moksony, F. (1990). Ecological analysis of suicide. In D. Lester (Ed.), Understanding suicide (pp. 121-138). Philadelphia, PA: Charles Press.

Moniruzzaman, S., \& Andersson, R. (2008). Economic development as a determinant of injury mortality-A longitudinal approach. Social Science \& Medicine, 66, 1699-1708 doi:10.1016/j.socscimed.2007.12.020

Morrell, S., Taylor, R., Slaytor, E., \& Ford, P. (1999). Urban and rural suicide differentials in migrants and the Australian-born, New South Wales, Australia 1985-1994. Social Science \& Medicine, 49, 81-91. doi:10.1016/S0277-9536(99)00083-0

Nakaya, N., Kikuchi, N., Shimazu, T., Ohmori, K., Kakizaki, M., Sone, T., \& Tsuji, I. (2007). Alcohol consumption and suicide mortality among Japanese men: The Ohsaki study. Alcohol, 41, 503-510. doi:10.1016/j.alcohol.2007.08.001

Neeleman, J. (1998). Regional suicide rates in the Netherlands: Does religion still play a role? International Journal of Epidemiology, 27, 466-472. doi:10.1093/ije/27.3.466

Neeleman, J., \& Lewis, G. (1999). Suicide, religion, and socioeconomic conditions. An ecological study in 26 countries, 1990. Journal of Epidemiology and Community Health, 53, 204-210. doi:10.1136/jech.53.4.204

Neeleman, J., Halpern, D., Leon, D., \& Lewis, G. (1997). Tolerance of suicide, religion and suicide rates: an ecological and individual study in 19 Western countries. Psychological Medicine, 27, 1165-1171. doi:10.1017/S0033291797005357

Neumayer, E. (2003). Socioeconomic factors and suicide rates at large-unit aggregate levels: A comment. Urban Studies, 40, 2769-2776. doi:10.1080/0042098032000191029

Newman, J. F., Whittemore, K. R., \& Newman, H. G. (1973). Women in the labor force and suicide. Social Problems, 21, 220-230. doi:10.2307/799541

Niederkrotenthaler, T., \& Sonneck, G. (2007). Assessing the impact of media guidelines for reporting on suicides in Austria: Interrupted time series analysis. Australian and New Zealand Journal of Psychiatry, 41, 419-428. doi:10.1080/00048670701266680

Niederkrotenthaler, T., Till, B., Kapusta, N. D., Voracek, M., Dervic, K., \& Sonneck, G. (2009). Copycat effects after media reports on suicide: A population-based ecologic study. Social Science \& Medicine, 69, 1085-1090. doi:10.1016/j.socscimed.2009.07.041

Niederkrotenthaler, T., Voracek, M., Herberth, A., Till, B., Strauss, M., Etzersdorfer, E., \& Sonneck, G. (2010). Media and suicide. Papageno v Werther effect. British Medical Journal, 341, c5841. doi:10.1136/bmj.c5841

Noh, Y.-H. (2009). Does unemployment increase suicide rates? The OECD panel evidence. Journal of Economic Psychology, 30, 575582. doi:10.1016/j.joep.2009.04.003

Nordentoft, M., Qin, P., Helweg-Larsen, K., \& Juel, K. (2006). Time- trends in method-specific suicide rates compared with the availability of specific compounds. The Danish experience. Nordic Journal of Psychiatry, 60, 97-106. doi:10.1080/08039480600600169

Nordentoft, M., Qin, P., Helweg-Larsen, K., \& Juel, K. (2007). Restrictions in means for suicide: An effective tool in preventing suicide: The Danish experience. Suicide \& Life-Threatening Behavior, 37, 688697. doi:10.1521/suli.2007.37.6.688

Norström, T., \& Skog, O.-J. (2001). Alcohol and mortality: Methodological and analytical issues in aggregate analyses. Addiction, 96, 517. doi:10.1080/09652140020021143

O’Reilly, D., Rosato, M., Connolly, S., \& Cardwell, C. (2008). Area factors and suicide: 5-year follow-up of the Northern Ireland population. The British Journal of Psychiatry, 192, 106-111. doi:10.1192/bjp.bp.107.040360

Ott, J. R. J., Winkler, V., Kyobutungi, C., Laki, J., \& Becher, H. (2008). Effects of residential changes and time patterns on external-cause mortality in migrants: Results of a German cohort study. Scandinavian Journal of Public Health, 36, 524-531. doi: $10.1177 / 1403494807087293$

Page, A., Morrell, S., Taylor, R., Carter, G., \& Dudley, M. (2006). Divergent trends in suicide by socio-economic status in Australia. Social Psychiatry and Psychiatric Epidemiology, 41, 911-917. doi:10.1007/s00127-006-0112-9

Page, A., Morrell, S., Taylor, R., Dudley, M., \& Carter, G. (2007). Further increases in rural suicide in young Australian adults: Secular trends, 1979-2003. Social Science \& Medicine, 65, 442-453. doi:10.1016/j.socscimed.2007.03.029

Pampel, F. C. (1998). National context, social change, and sex differences in suicide rates. American Sociological Review 63, 744-758. doi:10.2307/2657337

Payne, S., Swami, V., \& Stanistreet, D. L. (2008). The social construction of gender and its influence on suicide: A review of the literature. Journal of Men's Health, 5, 23-35. doi:10.1016/j.jomh.2007.11.002

Pearce, J., Barnett, R., \& Jones, I. (2007). Have urban/rural inequalities in suicide in New Zealand grown during the period 1980-2001? Social Science and Medicine, 65, 1807-1819. doi:10.1016/j.socscimed.2007.05.044

Peele, S. (1997). Utilizing culture and behaviour in epidemiological models of alcohol consumption and conseqences for Western nations. Alcohol and Alcoholism, 32, 51-64. doi:10.1093/oxfordjournals.alcalc.a008234

Phillips, A. (2009). Health status differentials across rural and remote Australia. Australian Journal of Rural Health, 17, 2-9. doi:10.1111/j.1440-1584.2008.01029.X

Phillips, M. R., Li, X., \& Zhang, Y. (2002). Suicide rates in China, 1995-99. The Lancet, 359, 835-840. doi:10.1016/S0140-6736(02)07954-0

Pirkis, J., \& Blood, R. W. (2001a). Suicide and the media. Part I: Reportage in nonfictional media. Crisis, 22, 146-154. doi:10.1027//0227-5910.22.4.146

Pirkis, J., \& Blood, R. W. (2001b). Suicide and the media. Part II: Portrayal in fictional media. Crisis, 22, 155-162. doi:10.1027//0227-5910.22.4.155

Pirkis, J., Blood, R. W., Beautrais, A., Burgess, P., \& Skehans, J. (2006). Media guidelines on the reporting of suicide. Crisis: The Journal of Crisis Intervention and Suicide Prevention, 27, 82-87. doi:10.1027/0227-5910.27.2.82

Platt, S., Micciolo, R., \& Tansella, M. (1992). Suicide and unemployment in Italy: Description, analysis and interpretation of recent trends. Social Science \& Medicine, 34, 1191-1201. doi:10.1016/0277-9536(92)90312-E

Pompili, M., Innamorati, M., Vichi, M., Masocco, M., Vanacore, N., Lester, D., \& Girardi, P. (2011). Inequalities and impact of socioeconomic-cultural factors in suicide rates across Italy. Crisis: The Journal of Crisis Intervention and Suicide Prevention, 32, 178-185. doi:10.1027/0227-5910/a000084

Preti, A., \& Miotto, P. (1999). Suicide and unemployment in Italy, 1982-1994. Journal of Epidemiology and Community Health, 53, 694701. doi:10.1136/jech.53.11.694

Pridemore, W. A. (2006). Heavy drinking and suicide in Russia. Social 
Forces, 85, 413-430 doi:10.1353/sof.2006.0138

Pritchard, C. (1992). Is there a link between suicide in young men and unemployment? A comparison of the UK with other European community countries. The British Journal of Psychiatry, 160, 750-756. doi:10.1192/bjp.160.6.750

Pritchard, C. (1996). Suicide in the People's Republic of China categorized by age and gender: Evidence of the influence of culture on suicide. Acta Psychiatrica Scandinavica, 93, 362-367. doi:10.1111/j.1600-0447.1996.tb10661.x

Pritchard, C., \& Baldwin, D. S. (2000). Effects of age and gender on elderly suicide rates in catholic and orthodox countries: An inadvertent neglect? International Journal Geriatric Psychiatry, 15, 904-910. doi:10.1002/1099-1166(200010)15:10<904::AID-GPS216>3.0.CO;2 $-\mathrm{O}$

Pugno, M. (2009). The Easterlin paradox and the decline of social capital: An integrated explanation. Journal of Socio-Economics, 38, 590-600. doi:10.1016/j.socec.2009.03.012

Qin, P., Agerbo, E., \& Mortensen, P. B. (2003). Suicide risk in relation to socioeconomic, demographic, psychiatric, and familial factors: A national register-based study of all suicides in Denmark, 1981-1997. American Journal of Psychiatry, 160, 765-772. doi:10.1176/appi.ajp.160.4.765

Qin, P., Mortensen, P. B., Agerbo, E., Westergard-Nielsen, N., \& Eriksson, T. O. R. (2000). Gender differences in risk factors for suicide in Denmark. World Development, 177, 546-550. doi:10.1192/bjp.177.6.546

Ramstedt, M. (2001). Alcohol and suicide in 14 European countries. Addiction, 96, s59-s79.

Roberts, D. M., Karunarathna, A., Buckley, N. A., Manuweera, G., Sheriff, M. H. R., \& Eddleston, M. (2003). Influence of pesticide regulation on acute poisoning deaths in Sri Lanka. Bulletin of the World Health Organization, 81, 789-798.

Rodríguez Andrés, A. (2005). Income inequality, unemployment, and suicide: A panel data analysis of 15 European countries Applied Economics, 37, 439-451. doi:10.1080/0003684042000295304

Rodríguez Andrés, A. R., \& Hempstead, K. (2011). Gun control and suicide: The impact of state firearm regulations in the United States. 1995-2004. Health Policy, 101, 95-103.

doi:10.1016/j.healthpol.2010.10.005

Rossow, L. (1996). Alcohol and suicide-beyond the link at the individual level. Addiction, 91, 1413-1416. doi:10.1111/j.1360-0443.1996.tb02240.x

Rubinstein, D. H. (1992). Suicide in Micronesia and Samoa: A critique of explanations. Pacific Studies, 15, 51-75.

Sareen, J., Afifi, T. O., McMillan, K. A., \& Asmundson, G. J. G. (2011). Relationship between household income and mental disorders: Findings from a population-based longitudinal study. Archives of General Psychiatry, 68, 419-427. doi:10.1001/archgenpsychiatry.2011.15

Saunderson, T., Haynes, R., \& Langford, I. H. (1998). Urban-rural variations in suicides and undetermined deaths in England and Wales. Journal of Public Health, 20, 261-267. doi:10.1093/oxfordjournals.pubmed.a024767

Shah, A. (2008). Association of suicide rates of elderly persons with fertility rates. Psychological Reports, 102, 369-376. doi:10.2466/pr0.102.2.369-376

Shah, A., Lindesay, J., \& Dennis, M. (2009). Comparison of elderly suicide rates among migrants in England and Wales with their country of origin. International Journal of Geriatric Psychiatry, 24, 292299. doi:10.1002/gps.2105

Sher, L. (2006). Per capita income is related to suicide rates in men but not in women. The Journal of Men's Health \& Gender, 3, 39-42. doi:10.1016/j.jmhg.2005.04.016

Singh, G., \& Siahpush, M. (2002). Increasing rural-urban gradients in US suicide mortality. American Journal of Public Health, 92, 11611168. doi:10.2105/AJPH.92.7.1161

Singh, G. K., \& Siahpush, M. (2006). All-cause and cause-specific mortality of immigrants and native born in the United States. American Journal of Public Health, 91, 392-399.

Skegg, K., \& Herbison, P. (2009). Effect of restricting access to a sui- cide jumping site. Australian and New Zealand Journal of Psychiatry, 43, 498-502. doi:10.1080/00048670902873698

Stack, S. (1981). The Effect of Immigration on Suicide: A cross-national analysis. Basic and Applied Social Psychology, 2, 205-218. doi:10.1207/s15324834basp0203_4

Stack, S. (1982). Suicide: A decade review of the sociological literature. Deviant Behavior, 4, 41-66. doi:10.1080/01639625.1982.9967602

Stack, S. (1987). The effect of female participation in the labor force on suicide: A time series analysis, 1948-1980. Sociological Forum, 2, 257-277. doi:10.1007/BF01124166

Stack, S. (1996-1997). Does being a parent affect suicide ideology? OMEGA: Journal of Death and Dying 34, 71-80. doi:10.2190/Y4MX-74WN-86BA-UGHB

Stack, S. (2000a). Suicide: A 15-year review of the sociological literature. Part 1: Cultural and economic factors. Suicide \& Life-Threatening Behavior, 30, 145-176.

Stack, S. (2000b). Suicide: A 15-year review of the sociological literature. Part II: Modernization and social integration perspectives. Suicide \& Life-Threatening Behavior, 30, 163-176.

Stack, S. (2005). Suicide in the media: A quantitative review of studies based on non-fictional stories. Suicide \& Life-Threatening Behavior, 35, 121-133. doi:10.1521/suli.35.2.121.62877

Stack, S. (2009). Copycat effects of fictional suicide: A meta-analysis. In S. Stack, \& D. Lester (Eds.), Suicide and the creative arts (pp. 231-243). New York: Nova Science.

Stickley, A., Jukkala, T., \& Norstrom, T. (2011). Alcohol and suicide in Russia, 1870-1894 and 1956-2005: Evidence for the continuation of a harmful drinking culture across time? Journal of Studies on Alcohol and Drugs, 72, 341-347.

Stockard, J., \& O'Brien, R. M. (2002). Cohort effects on suicide rates: International variations. American Sociological Review, 67, 854-872. doi:10.2307/3088973

Stuckler, D., Basu, S., Suhrcke, M., Coutts, A., \& McKee, M. (2009). The public health effect of economic crises and alternative policy responses in Europe: An empirical analysis. The Lancet, 374, 315-323. doi:10.1016/S0140-6736(09)61124-7

Sudak, H. S., \& Sudak, D. M. (2005). The media and suicide. Academic Psychiatry, 29, 495-499. doi:10.1176/appi.ap.29.5.495

Tapia Granados, J. A., \& Diez Roux, A. V. (2009). Life and death during the Great Depression. Proceedings of the National Academy of Sciences of the United States of America, 106, 17290-17295. doi:10.1073/pnas.0904491106

Taylor, R., Morrell, S., Slaytor, E., \& Ford, P. (1998). Suicide in urban New South Wales, Australia 1985-1994: Socio-economic and migrant interactions. Social Science and Medicine, 47, 1677-1686. doi:10.1016/S0277-9536(98)00243-3

Trovato, F. (1987). A longitudinal analysis of divorce and suicide in Canada. Journal of Marriage and Family, 49, 193-203. doi:10.2307/352683

Trovato, F., \& Jarvis, G. K. (1986). Immigrant suicide in Canada: 1971 and 1981. Social Forces, 65, 433-457.

Trovato, F., \& Vos, R. (1992). Married female labor force participation and suicide in Canada, 1971 and 1981. Sociological Forum, 7, 661677. doi:10.1007/BF01112320

Tsai, J.-F., \& Cho, W. (2011). The secular trend of suicide rate and the socio-economic, media, and climatic factors in Taiwan, 1976-2009: A population-based study. Journal of Affective Disorders, 129, 270274. doi:10.1016/j.jad.2010.08.008

Umberson, D. (1987). Family Status and Health Behaviors: Social control as a dimension of social integration. Journal of Health and Social Behavior, 28, 306-319. doi:10.2307/2136848

Van Poppel, F., \& Day, L. H. (1996). A test of Durkheim's theory of suicide-Without committing the "ecological fallacy". American Sociological Review, 61, 500-508. doi:10.2307/2096361

Van Tubergen, F., Te Grotenhuis, M., \& Ultee, W. (2005). Denomination, religious context, and suicide: Neo-Durkheimian multilevel Explanations tested with individual and contextual data. American Journal of Sociology, 111, 797-823. doi:10.1086/497307

Vijayakumar, L., Nagaraj, K., Pirkis, J., \& Whiteford, H. (2005). Suicide in developing countries (1): Frequency, distribution, and asso- 
ciation with socioeconomic indicators. Crisis, 26, 104-111. doi:10.1027/0227-5910.26.3.104

Voracek, M., \& Loibl, L. M. (2008). Consistency of immigrant and country-of-birth suicide rates: A meta-analysis. Acta Psychiatrica Scandinavica, 118, 259-271. doi:10.1111/j.1600-0447.2008.01238.x

Westman, J., Sundquist, J., Johansson, L. M., Johansson, S. E., \& Sundquist, K. (2006). Country of birth and suicide: A follow-up study of a national cohort in Sweden. Archives of Suicide Research, 10, 239-248. doi:10.1080/13811110600582471

Whitley, E., Gunnell, D., Dorling, D., \& Smith, G. D. (1999). Ecological study of social fragmentation, poverty, and suicide. British Medical Journal, 319, 1034-1037. doi:10.1136/bmj.319.7216.1034

Wilkinson, R. G. (1997). Health inequalities: Relative or absolute material standards? British Medical Journal, 315, 591-595. doi:10.1136/bmj.314.7080.591

Wong, P. W. C., Chan, W. S. C., Lau, T. K., Morgan, P. R., \& Yip, P. S. F. (2009). Suicides by jumping from iconic bridges in Hong Kong. Crisis: The Journal of Crisis Intervention and Suicide Prevention, 30, 79-84. doi:10.1027/0227-5910.30.2.79

Wu, W. C., \& Bond, M. H. (2006). National differences in predictors of suicide among young and elderly citizens: Linking societal predictors to psychological factors. Archives of Suicide Research, 10, 45-60. doi:10.1080/13811110500318430

Wyder, M., Ward, P., \& De Leo, D. (2009). Separation as a suicide risk factor. Journal of Affective Disorders, 116, 208-213. doi:10.1016/j.jad.2008.11.007

Yamasaki, A., Araki, S., Sakai, R., \& Voorhees, S. (2008). Corrigendum: Suicide mortality of young, middle-aged and elderly males and females in Japan for the years 1953-96: Time series analysis for the effects of unemployment, female labour force, young and aged population, primary industry and population density. Industrial Health, 46, 541-549. doi:10.2486/indhealth.46.541

Yamasaki, A., Sakai, R., \& Shirakawa, T. (2005). Low income, unemployment, and suicide mortality rates for middle-age persons in Japan. Psychological Reports, 96, 337-348. doi:10.2466/pr0.96.2.337-348

Yang, B., \& Lester, D. (2001). Learnings from Durkheim and beyond: The economy and suicide. Suicide \& Life-Threatening Behavior, 31, 15-31. doi:10.1521/suli.31.1.15.21306

Ying, Y. H., \& Chang, K. (2009). A study of suicide and socioeconomic factors. Suicide \& Life-Threatening Behavior, 39, 214-226. doi:10.1521/suli.2009.39.2.214

Yip, P. S., Fu, K. W., Yang, K. C., Ip, B. Y., Chan, C. L., Chen, E. Y., \& Hawton, K. (2006). The effects of a celebrity suicide on suicide rates in Hong Kong. Journal of Affective Disorders, 93, 245-252. doi:10.1016/j.jad.2006.03.015

Yip, P. S. F., Callanan, C., \& Yuen, H. P. (2000). Urban/rural and gender differentials in suicide rates: East and west. Journal of Affective Disorders, 57, 99-106. doi:10.1016/S0165-0327(99)00058-0

Zhang, J. (1998). Suicide in the world: Toward a population increase theory of suicide. Death Studies, 22, 525-539. doi:10.1080/074811898201380

Zhang, J. (2010). Marriage and suicide among Chinese rural young women. Social Forces, 89, 311-326. doi:10.1353/sof.2010.0065

Zhang, J., Ma, J., Jia, C., Sun, J., Guo, X., Xu, A., \& Li, W. (2010) Economic growth and suicide rate changes: A case in China from 1982 to 2005. European Psychiatry, 25, 159-163. doi:10.1016/j.eurpsy.2009.07.013 